Jpn J Human Genet 42, 317-322, 1997

\title{
MUCOPOLYSACCHARIDOSIS IVA: A NOVEL SPLICE ACCEPTOR SITE MUTATION IN INTRON 4 OF THE $N$-ACETYLGALACTOSAMINE-6-SULFATE SULFATASE GENE IN AN AFGHANISTAN GIRL WITH CLASSICAL MORQUIO DISEASE
}

\author{
Seiji Fukuda,,$^{1, *}$ Naoto Yamada, ${ }^{1}$ Shunji Tomatsu, ${ }^{1}$ \\ Kazuko Sukegawa, ${ }^{1}$ Adriana Maria Montaño, ${ }^{1}$ John J. Hopwood, ${ }^{2}$ \\ Vivenne MULleR, ${ }^{2}$ Tadao ORII, ${ }^{3}$ and Naomi KONDO ${ }^{1}$ \\ ${ }^{1}$ Department of Pediatrics, Gifu University, School of Medicine, \\ 40 Tsukasa-machi, Gifu 500, Japan \\ ${ }^{2}$ Department of Chemical Pathology, Women's and Children's Hospital, \\ 72 King William Road, North Adelaide, South Australia 5006, Australia \\ ${ }^{3}$ Chubu Women's College, 4909-3 Mukaiyama, Kurachi, Seki 501-32, Japan
}

Summary We report here a novel splice site mutation in intron 4 of the gene for $N$-acetylgalactosamine-6-sulfate sulfatase (GALNS) in an Afghanistan girl with severe mucopolysaccharidosis IVA (classical Morquio disease). Direct sequencing revealed a homozygous $G$ to $A$ transition in the conserved splice acceptor site in intron 4 (cagG $\rightarrow$ caaG: designated IVS $4(-1) \mathrm{G} \rightarrow \mathrm{A}$ ) which eliminates 144 nucleotides of exon 5 in her GALNS transcript and introduces an immediate premature termination codon (at $\operatorname{Trp} 141$ of exon 4). The IVS $4(-1) \mathrm{G} \rightarrow \mathrm{A}$ has not been seen in other populations and this is the first report of the molecular basis of classical Morquio disease in an Afghanistan patient.

Key Words mucopolysaccharidosis IVA, splice site mutation, $N$ acetylgalactosamine-6-sulfate sulfatase, Morquio disease

\section{INTRODUCTION}

Mucopolysaccharidosis IVA (MPSIVA: Morquio disease) is an autosomal recessive lysosomal storage disorder and is characterized by the lack of activity of $N$-acetylgalactosamine-6-sulfate sulfatase (GALNS: EC 3.1.6.4) (Matalon et al., 1974). Typical clinical manifestations include coxa valga, odontoid hypoplasia, short trunk dwarfism, accumulating undegraded keratan sulfate and chondroitin-6sulfate in the lysosomes (Morquio, 1929; Maroteaux and Lamy, 1967). On the basis of clinical signs as well as age of onset, three forms severe classical (Morquio,

Received January 6, 1997; Revised version accepted March 11, 1997.

* To whom correspondence should be addressed. 
1929), intermediate (Glössl et al., 1981) and mild Morquio disease (Orii et al., 1981; Hechit et al., 1984; Beck et al., 1986) can be distinguished. The phenotypic heterogeneity suggests that multiple allelic mutations are responsible for the disease. The analysis of cDNA and genomic DNA structure and organization have made it feasible to study mutations in the GALNS gene (Tomatsu et al., 1991; Nakashima et al., 1994), and over 30 different mutations that underlie MPSIVA have been identified in Japanese, British, Italian, Pakistan and Canadian patients (Fukuda et al., 1992, 1996a, b; Ogawa et al., 1995; Hori et al., 1995; Tomatsu et al., 1994a, b, 1995a, b, c, d, 1996; Cole et al., 1996). Most of the mutations are population specific, supporting a hypothesis that they have developed independently in different ethnic groups. Our purpose is to investigate the molecular basis of MPSIVA as well as to characterize the distribution of mutant alleles and their origins among various populations. Here we report an Afghanistan girl with classical Morquio disease harboring a novel homozygous mutation at the splice acceptor site of intron 4 in the GALNS gene. This is the first documentation of the molecular basis of Morquio disease in the Afghan population.

\section{MATERIALS AND METHODS}

At age 7 years the patient whose parents were first cousins was diagnosed as having Morquio disease, based on findings of keratan sulfaturia and deficient activity of GALNS. She was $82 \mathrm{~cm}$ tall at 7 years, and showed marked hyperlaxity of wrists, elbows and ankles, and thoracic kyphoscoliosis. There was no facial dysmorphism or hepatosplenomegaly. X-rays revealed platyspondyly. The pathogenic mutation was searched for by genomic PCR as well as RT-PCR, and subsequent SSCP analysis (Ogawa et al., 1995). A pair of primers for RT.PCR were designed as OMF 3: 5'-TTGGACCGGATGGCTGCAGAA-3' and OMF25: 5'-GCCCGCAAGGGCCAGGCTGGT-3'. The mutation was determined by direct sequencing using an automated sequencer (Perkin Elmer, Applied Biosystems). Since the mutation found in the present study eliminates an $M v a$ I restriction site, genomic PCR fragments obtained from the patient and her parents were digested by $M v a \mathrm{I}$ and vizualized in an $8 \%$ acrylamide gel to detect the mutant allele. Haplotypes of the GALNS gene were constructed as described (Rezvi et al., 1996).

\section{RESULTS AND DISCUSSION}

An abnormal band was observed only in a PCR-SSCP fragment containing exon 5 and its exon/intron boundary. Direct sequencing revealed a $G$ to $A$ transition in the conserved splice acceptor site in intron 4 ( $\mathrm{cagG} \rightarrow$ caaG: designated IVS $4(-1) \mathrm{G} \rightarrow \mathrm{A}$ ), the result strongly suggesting that the patient is homozygous for this mutation (Fig. 1). When we compared the mutation site with the wild-type 
sequence, the mutant splice site score was reduced from 95.1 to 79.1 (Shapiro and Senapathy, 1987). This mutation is expected to make correct splicing of GALNS mRNA impossible by activating a cryptic acceptor site in exon 5 or by skipping

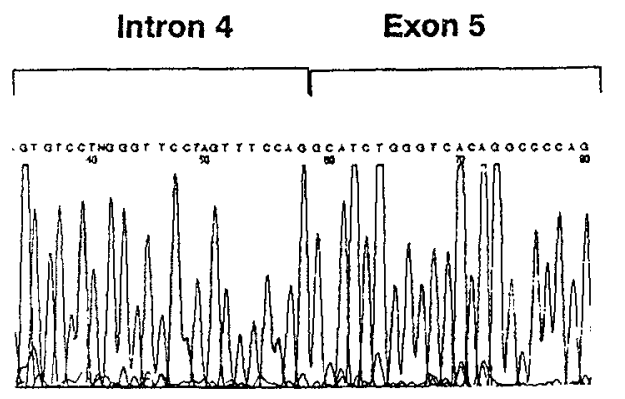

Normal
Intron $4 \quad$ Exon 5

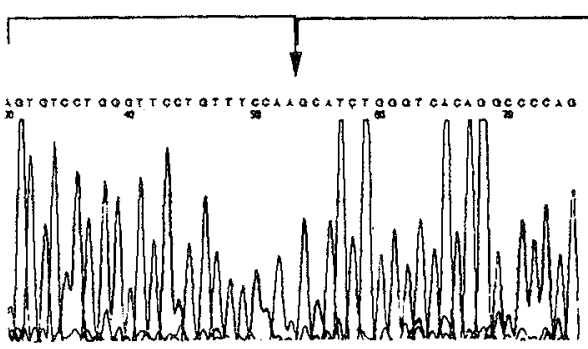

Mutant

\section{Normal : g t t c ctg t t t c a g G CA \\ Mutant : g t t c ctg t t t c ca a G CA}

Fig. 1. Nucleotide sequence of splice acceptor site mutation in intron 4 . Lower case letters indicate sequence of intron 4 and the upper cases stand for exon 5 . The altered nucleotides at the splice junction are underlined. Arrows indicates the mutation in the sequence.

exon $4 \quad$ exon 6

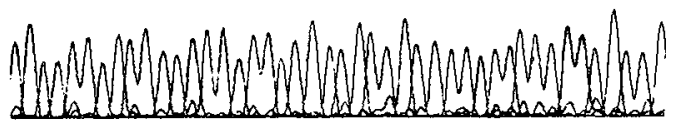

1

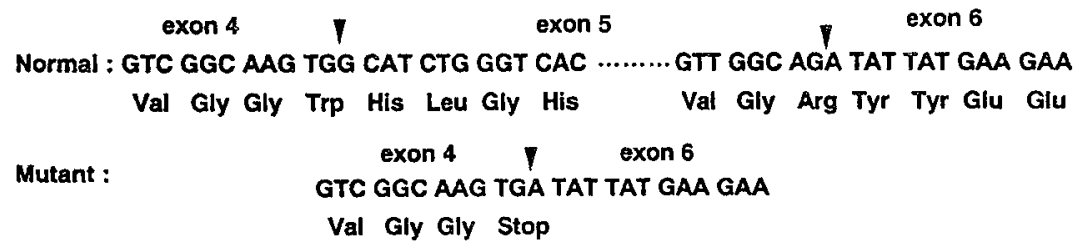

Fig. 2. Sequence of the transcript including skipping of exon 5 and direct splicing of exon 4 to exon 6 . Note that pretermination is introduced as a result of exon skipping. Arrows represents the junction of exon 5 skipping. Arrowheads indicates junction of each exon.

Vol. 42, No. 2, 1997 
of exon 5 and direct splicing of exon 4 to exon 6 in the mutant mRNA. Only a smaller band than expected size was amplified by RT-PCR and 144 nucleotides of exon 5 were completely absent in the GALNS transcript, demonstrating that IVS $4(-1) \mathrm{G} \rightarrow \mathrm{A}$ at the splice acceptor site in intron 4 leads to exon 5 skipping. This mutation introduces an immediate premature termination codon (at $\operatorname{Trp} 141$ of exon 4), which deletes 382 residues at the C-terminal region, most likely resulting in the deficient allele (Fig. 2). Thus, we conclude that the novel IVS $4(-1) \mathrm{G} \rightarrow$ A mutation is causative for GALNS deficiency in this severely affected patient. Genomic PCR coupled with $M v a$ I restriction analysis for her parents revealed that they were heterozygous carriers for the mutation, thus confirming that the patient is homozygous (Fig. 3). The IVS 4(-1) G $\rightarrow$ A substitution was on haplotype 2, the most frequent haplotype in Caucasian (Rezvi et al., 1996).

Most mutations identified to date are rare, although some of them were common in specific ethnic groups (Tomatsu et al., 1995d, 1996). The IVS 4(-1) $\mathrm{G} \rightarrow \mathrm{A}$ is a novel mutation that has not been found in other populations. It is not clear whether IVS $4(-1) \mathrm{G} \rightarrow \mathrm{A}$ is predominant in the Afghan population. However, a screening of mutations in a number of patients in Afghanistan or surrounding areas coupled with haplotype analysis will facilitate more precise

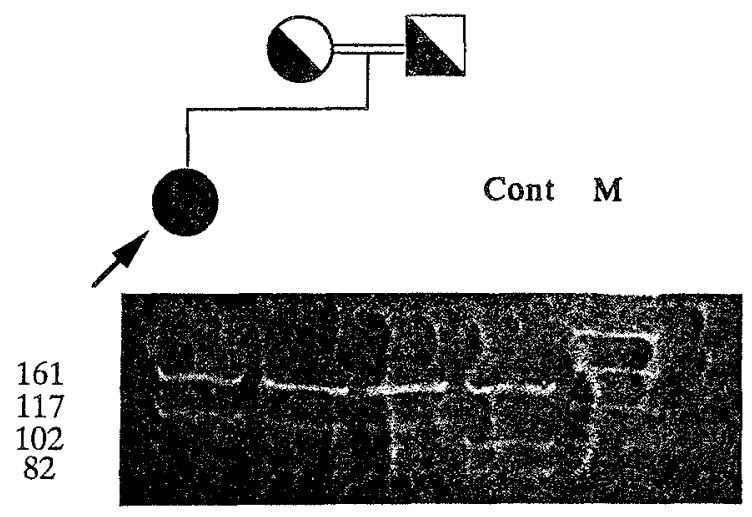

\begin{tabular}{cc|c|c|c|c|}
\multirow{2}{*}{ Normal } & \multicolumn{2}{c}{ Mval Mval } & \multicolumn{2}{c}{ Mval } & \multicolumn{2}{c|}{ Mval } \\
\cline { 2 - 6 } & 52 & 15 & 102 & 161 & 82 \\
\cline { 2 - 6 } & \multicolumn{3}{c}{ Mval } & \multicolumn{3}{c}{ Mval } & \multicolumn{2}{c|}{ Mval } \\
Mutant & 52 & 117 & 161 & 82 \\
\hline
\end{tabular}

Fig. 3. MvaI restriction analysis of family members. Genomic PCR DNA including IVS $4(-1) \mathrm{G} \rightarrow \mathrm{A}$ were subjected to $M v a$ I digestion. $117 \mathrm{bp}$ and 102 bp bands stand for mutant and normal allele, respectively. Cont: control subject. M: Size marker pUC13/HapII digest. 
detection of carriers and prediction of the development of the disease.

Acknowledgments We thank Dr. A. Bankier of the Monash Medical Centre, Victoria, Australia for providing patient information and skin fibroblasts, M. Ohara for helpful comments and C. Kozakai for technical service. This work was supported in part by Grants-in-Aid for Scientific Research (08770552 and 08670869) from the Ministry of Education, Science, Sports and Culture of Japan and from the National Health and Medical Research Council of Australia.

\section{REFERENCES}

Beck M, Glössl J, Grubisic A, Spranger J (1986): Heterogeneity of Morquio disease. Clin Genet 29: 325-331

Cole DEC, Fukuda S, Gordon BA, Rip JW, LeCouteur AN, Rupar CA, Tomatsu S, Ogawa T, Sukegawa K, Orii T (1996): Heteroallelic missense mutations of the galactosamine-6-sulfate sulfatase (GALNS) gene in a mild form of Morquio disease (MPSIVA). Am $J$ Med Genet 63: $558-565$

Fukuda S, Tomatsu S, Masue M, Sukegawa K, Iwata H, Ogawa T, Nakashima Y, Hori T, Yamagishi A, Hanyu Y, Morooka K, Kiman T, Hashimoto T, Orii T (1992): Mucopolysaccharidosis IVA $N$-acetylgalactosamine-6-sulfate sulfatase exonic point mutations in classical Morquio and mild cases. J Clin Invest 90: 1049-1053

Fukuda S, Tomatsu S, Masuno M, Ogawa T, Yamagishi A, Rezvi GMM, Sukegawa K, Shimozawa N, Suzuki Y, Kondo N, Imaizumi K, Kuroki Y, Okabe T, Orii T (1996a): Mucopolysaccharidosis IVA: Submicroscopic deletion of $16 \mathrm{q} 24.3$ and a novel R386C mutation of $N$ acetylgalactosamine-6-sulfate sulfatase gene in a classical Morquio disease. Hum Mutat 7: $123-134$

Fukuda S, Tomatsu S, Cooper A, Wraith JE, Kato Z, Yamada N, Isogai K, Sukegawa K, Kondo N, Orii T (1996b): Mucopolysaccharidosis IVA (Morquio A): Three novel small deletions in the $N$-acetylgalactosamine-6-sulfate sulfatase gene. Hum Mutat 8: 187-190

Glössl J, Maroteaux P, Di Natale P, Kresse H (1981): Different properties of residual $N$-acetylgalactosamine-6-sulfate sulfatase in fibroblasts from patients with mild and severe forms of Morquio disease type A. Pediatr Res 15: 976-978

Hechit JT, Scott CI, Smith TK, Williams IC (1984): Mild manifestations of the Morquio syndrome. Am J Med Genet 18: 369-371

Hori T, Tomatsu S, Nakashima Y, Uchiyama A, Fukuda S, Sukegawa K, Shimozawa N, Suzuki Y, Kondo N, Horiuchi T, Ogura S, Orii T (1995): Mucopolysaccharidosis type IVA: Common double deletion in the $N$-acetylgalactosamine-6-sulfate sulfatase gene (GALNS). Genomics 26: 535-542

Maroteaux P, Lamy M (1967): Studying the mucopolysaccharidoses. Lancet ii: 510

Matalon R, Arbogast B, Justuce P, Brandt IK, Dorfman A (1974): Morquio's syndrome: deficiency of a chondroitin sulfate $N$-acetylhexosamine sulfate sulfatase. Biochem Biophys Res Commun 61: 709-715

Morquio L (1929): Sur une forme de dystrophie osseuse familiale. Bull Soc Pediatr Paris 27: 145152

Nakashima Y, Tomatsu S, Hori T, Fukuda S, Sukegawa K, Kondo N, Suzuki Y, Shimozawa N, Orii T (1994): Mucopolysaccharidosis IVA: Molecular cloning of the human $N$-acetylgalactosamine-6-sulfatase gene (GALNS) and analysis of the $5^{\prime}$-flanking region. Genomics 20 : 99-104

Ogawa T, Tomatsu S, Fukuda S, Yamagishi A, Rezvi GMM, Sukegawa K, Kondo N, Suzuki Y, Shimozawa N, Orii T (1995): Mucopolysaccharidosis IVA: screening and identification of mutations of the $N$-acetylgalactosamine-6-sulfate sulfatase gene. Hum Mol Genet 4: 341-349

Orii T, Kiman T, Sukegawa K, Kanemura T, Hattori S, Taga T, Ko K (1981): Late onset $N$ acetylgalactosamine-6-sulfate sulfatase deficiency in two brothers. Connect Tissue 13: 169175

Vol. 42, No. 2, 1997 
Rezvi GMM, Tomatsu S, Fukuda S, Yamagishi A, Cooper A, Wraith JE, Iwata H, Kato Z, Yamada N, Sukegawa K, Shimozawa N, Suzuki Y, Kondo N, Orii T (1996): Mucopolysaccharidosis IVA: a comparative study of polymorphic DNA haplotypes in the Caucasian and Japanese populations. J Inherited Metab Dis 19: 301-308

Shapiro MB, Senapathy P (1987): RNA splice junctions of different classes of eukaryotes: sequence statistics and functional implications in gene expression. Nucleic Acids Res 5: $7155-7174$

Tomatsu S, Fukuda S, Masue M, Sukegawa K, Fukao T, Yamagishi A, Hori T, Iwata H, Ogawa T, Nakashima Y, Hanyu Y, Hashimoto T, Titani K, Oyama R, Suzuki M, Yagi K, Hayashi $Y$, Orii T (1991): Morquio disease: isolation, characterization and expression of full-length cDNA for human $N$-acetylgalactosamine-6-sulfate sulfatase. Biochem Biophys Res Commum 181: $677-683$

Tomatsu S, Fukuda S, Ogawa T, Kato Z, Isogai K, Kondo N, Suzuki Y, Shimozawa N, Sukegawa K, Orii T (1994a): A novel splice site mutation in intron 1 of the GALNS gene in a Japanese patient with mucopolysaccharidosis IVA. Hum Mol Genet 3 (8): 1427-1428

Tomatsu S, Fukuda S, Uchiyama A, Hori T, Nakashima Y, Kondo N, Suzuki Y, Shimozawa N, Sukegawa K, Orii T (1994b): Molecular analysis by Southern blot for the $N$-acetylgalactosamine-6-sulfate sulfatase gene causing mucopolysaccharidosis IVA in the Japanese population. J Inherited Metab Dis 17: 60l-605

Tomatsu S, Fukuda S, Cooper A, Wraith JE, Rezvi GMM, Yamagishi A, Yamada N, Kato Z, Isogai K, Sukegawa K, Kondo N, Suzuki Y, Shimozawa N, Orii T (1995a): Mucopolysaccharidosis IVA: identification of six novel mutations among non-Japanese patients. Hum Mol Genet 4: 741-743

Tomatsu S, Fukuda S, Cooper A, Wraith JE, Uchiyama A, Hori T, Nakashima Y, Yamada N, Sukegawa K, Kondo N, Suzuki Y, Shimozawa N, Orii T (1995b): Mucopolysaccharidosis IVA: structural gene alterations identified by Southern blot analysis and identification of racial differences. Hum Genet 95: 376-381

Tomatsu S, Fukuda S, Cooper A, Wraith JE, Yamada N, Isogai K, Kato Z, Sukegawa K, Kondo N, Suzuki Y, Shimozawa N, Orii T (1995c): Two new mutations, Q473X and N487S, in a Caucasian patient with mucopolysaccharidosis IVA (Morquio disease). Hum Mutat 6: 195196

Tomatsu S, Fukuda S, Cooper A, Wraith JE, Rezvi GMM, Yamagishi A, Yamada N, Kato Z, Isogai K, Sukegawa K, Kondo N, Suzuki Y, Shimozawa N, Orii T (1995d): Mucopolysaccharidosis IVA: identification of a common missense mutation I113F in the $N$-acetylgalactosamine-6-sulfate sulfatase gene. Am J Hum Genet 57: 556-563

Tomatsu S, Fukuda S, Yamagishi A, Cooper A, Wraith JE, Hori T, Kato Z, Yamada N, Isogai K, Sukegawa K, Kondo N, Suzuki Y, Shimozawa N, Orii T (1996): Mucopolysaccharidosis IVA: Four new exonic mutations in patients with $N$-acetylgalactosamine-6-sulfate sulfatase deficiency. Am J Hum Genet 58: 950-962 